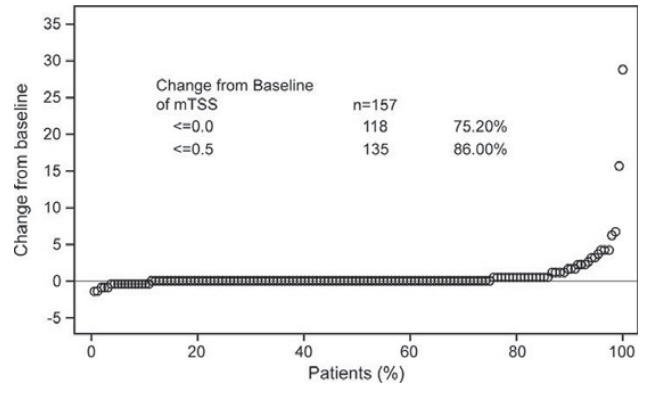

Tanabe, Takeda, Daiichi-Sankyo, Chugai, Bristol-Myers, MSD, Astellas, Abbvie, Eisai, Consultant for: Abbvie, Chugai, Daiichi-Sankyo, Bristol-Myers, Mitsubishi Tanabe, Astellas, Takeda, Pfizer, Teijin, Asahi-kasei, YL Biologics, Sanofi, Janssen, Eli Lilly, GlaxoSmithKline, T. Mimori Grant/research support from: Acterion, Ayumi, Astellas, Bristol-Myers Squibb, Chugai, Daiichi-Sankyo, Eisai, Mitsubishi Tanabe, Speakers bureau: Chugai, Mitsubishi Tanabe, H. Yamanaka Grant/research support from: MSD, Ayumi, AbbVie, Eisai, Ono, Astellas, DaiichiSankyo, Taisyo-Toyama, Takeda, Tanabe-Mitsubishi, Chugai, Teijin Pharma, Torii, Nippon Shinyaku, Pfizer, UCB. Nippon Kayaku, YL biologics, Bayer, BristolMeyers, Consultant for: MSD, Ayumi, AbbVie, Eisai, Ono, Astellas, Daiichi-Sankyo, Taisyo-Toyama, Takeda, Tanabe-Mitsubishi, Chugai, Teijin Pharma, Torii, Nippon Shinyaku, Pfizer, UCB, Nippon Kayaku, YL biologics, Bayer, Bristol-Meyers, R. Nakajima Employee of: AbbVie GK, K. Morita Employee of: AbbVie GK, J. Kimura Employee of: AbbVie GK, T. Takeuchi Grant/research support from: AbbVie, Astellas, Bristol-Myers, Chugai, Daiichi Sankyo, Eisai, Janssen, Mitsubishi Tanabe, Nippon Shinyaku, Pfizer, Sanofi, Santen, Takeda, Teijin, Consultant for: AstraZeneca, Eli Lilly, Novartis, Mitsubishi Tanabe, Asahi Kasei Medical, Speakers bureau: AbbVie, Bristol-Myers Squibb, Chugai, Eisai, Janssen, Mitsubishi Tanabe, Pfizer, Takeda

DOI: 10.1136/annrheumdis-2017-eular.4579

\section{FRI0211 A DESCRIPTIVE ANALYSIS OF REAL-WORLD TREATMENT PATTERNS OF INNOVATOR INFLIXIMAB (REMICADE) AND BIOSIMILAR INFLIXIMAB IN A TREATMENT NAÏVE TURKISH RHEUMATOLOGIC DISEASE POPULATION}

Y. Yazici ${ }^{1}$, L. Xie ${ }^{2}$, A. Ogbomo ${ }^{2}$, D. Parenti ${ }^{3}$, K. Goyal ${ }^{3}$, A. Teeple ${ }^{3}$, L. Ellis ${ }^{3}$, 1. Simsek ${ }^{4} .{ }^{1}$ NYU Hospital for Joint Diseases, New York; ${ }^{2}$ STATinMED Research Inc, Ann Arbor; ${ }^{3}$ Janssen Scientific Affairs, LLC, Horsham, United States;

${ }^{4}$ Guven Hospital, Ankara, Turkey

Objectives: This retrospective healthcare claims analysis examined treatment patterns of innovator infliximab (IFX) and biosimilar infliximab (CT-P13) in a Turkish rheumatologic disease population after CT-P13 availability in July, 2014. Methods: Adult patients (pts) with $\geq 1$ diagnosis code (ICD-10-CM) for rheumatoid arthritis (RA) were identified in a national Turkish healthcare database during the study period (01DEC2010-01DEC2015). Eligible pts had continuous medi$\mathrm{cal} /$ pharmacy enrollment $\geq 12$ months before and $\geq 6$ months after IFX or CT-P13 initiation (index date). Patients were naïve to IFX or CT-P13 (i.e. had no IFX or CT-P13 within 12 months before the index date). Demographics, concomitant diseases and medications, and treatment patterns, eg., dose, interval, discontinuation, and switch were summarized. Confirmed discontinuation was defined as a switch to another biologic medication or the absence of an index biologic claim for $\geq 120$ days without censoring.

Results: Key results are shown in the Table. A total of 1044 patients initiated either medication. The majority $(80 \% ; n=831)$ initiated IFX. The IFX cohort had a mean age of 42 years; $56 \%$ were women and mean follow up was 12 months. The CT-P13 cohort consisted of 213 pts with mean age of 43 years; $58 \%$ women; and mean follow up of 9 months. Approximately one-third of pts in each cohort had a concomitant diagnosis of ankylosing spondylitis (AS; TABLE). Other concomitant diseases and medications appeared balanced between cohorts. Pts in the IFX cohort had an average of 5.2 infusions and mean dose of 4.7 vials per infusion approximately every 8 weeks. Pts in the CT-P13 cohort had an average of 3.6 doses and mean dose of 5.8 vials per dispensing approximately 9 weeks apart. A confirmed discontinuation occurred in $55 \%$ of the IFX cohort; driven in part by switching. $24 \%$ of IFX pts had $\geq 1$ biologic switch with $8 \%$ initially switching to CT-P13. Time to any discontinuation or censoring of IFX is shown in the Table. In the CT-P13 cohort, a confirmed discontinuation was observed in $63 \% ; 31 \%$ switched to another biologic therapy; and $20 \%$ initially switched to IFX. Time to any discontinuation or censoring of CT-P13 is shown in the Table.

Conclusions: These findings in a single country indicate that real world utilization patterns may differ between innovator IFX and CT-P13, with predominantly more patients initiating IFX; greater overall CT-P13 discontinuation and a higher proportion of patients switching from CT-P13 to IFX. Further studies are needed to understand the reasons for these observed differences.

Disclosure of Interest: Y. Yazici Grant/research support from: Janssen Scientific Affairs, LLC, L. Xie Consultant for: Janssen Scientific Affairs, LLC, A. Ogbomo Consultant for: Janssen Scientific Affairs, LLC, D. Parenti Employee of: Janssen Scientific Affairs, LLC, K. Goyal Employee of: Janssen Scientific Affairs, LLC, A.

\begin{tabular}{|l|c|c|c|c|c|}
\hline \multirow{2}{*}{ Female } & \multicolumn{2}{|c|}{$\begin{array}{c}\text { Innovator IFX Cohort } \\
\text { (N= 831) }\end{array}$} & \multicolumn{2}{c|}{ CT-P13cohort } \\
(N=213)
\end{tabular}

Teeple Employee of: Janssen Scientific Affairs, LLC, L. Ellis Employee of: Janssen Scientific Affairs, LLC, I. Simsek Grant/research support from: Janssen Scientific Affairs, LLC

DOI: 10.1136/annrheumdis-2017-eular.1117

\section{FRIDAY, 16 JUNE 2017 \\ Rheumatoid arthritis - other biologic treatment}

\section{FRI0212 COMPARATIVE EFFECTIVENESS OF FIRST-LINE BIOLOGIC MONOTHERAPY IN RHEUMATOID ARTHRITIS}

E. Silvagni ${ }^{1}$, A. Bortoluzzi ${ }^{1}$, G. Carrara ${ }^{2}$, M. Govoni ${ }^{1}$, C. Scirè ${ }^{1,3} \cdot{ }^{1}$ 1Department of Medical Science, Rheumatology Unit, University of Ferrara and Azienda Ospedaliero-Universitaria Sant'anna, Cona (Ferrara), ITALY, Ferrara (FE);

${ }^{2}$ Epidemiology Unit, Italian Society for Rheumatology; ${ }^{3}$ Epidemiology Unit, Italian Society for Rheumatology, Milan, Italy

Background: Non-Biological disease modifying antirheumatic drugs (csDMARDs) are recommended in association to biologics (bDMARDS) in the treatment of Rheumatoid Arthritis (RA) and combination therapy is superior than bDMARD monotherapy with a better drug survival. Limited data are available in literature about the best biological treatment choice when a monotherapy is necessary in biologic-naïve patients.

Objectives: To assess comparative effectiveness (drug survival) of different firstline bDMARDs when administered in monotherapy in a large population-based sample of RA deriving from the administrative health database of the Lombardy region in Italy.

Methods: Data were obtained from health database of the Lombardy Region between $1 / 1 / 2004$ and 31/12/2013. Patients with RA, diagnosed by a rheumatologist, with a certified diagnosis (exemption code 006.714.0) and treated with first-line approved bDMARDs (Abatacept [ABA], Adalimumab [ADA], Certolizumab [CTZ], Etanercept [ETA], Golimumab [GOL], Infliximab [INF] and Tocilizumab [TCZ]) were included; the presence of a combination therapy of any duration with a concomitant csDMARD (Methotrexate, Leflunomide, Sulfasalazine, Cyclosporine and Hydroxychloroquine) was compared to monotherapy. Clinical characteristics recorded were age, sex, disease duration, Charlson Comorbidity Index, hospitalization for bacterial infections, use of concomitant glucocorticoid (GCs) or Nonsteroidal Anti-Inflammatory Drugs (NSAIDs). Propensity to treatment with monotherapy was assessed by logistic models and results were presented as odds ratios and $95 \%$ confidence intervals $(\mathrm{Cl})$ Effectiveness was evaluated as drug survival using Cox proportional hazard models.

Results are presented as hazard ratios $(\mathrm{HR})$ and $\mathrm{Cl}$, crude and adjusted for pre-specified confounders.

Results: 4478 RA patients who started a first-line bDMARD were included; $840(18.8 \%)$ in monotherapy and $3638(81.2 \%)$ in association to at least one csDMARD. Among biologic-naïve monotherapy patients, N.398 (47.4\%) received ETA, N.215 (25.6\%) ADA, N.92 (10.9\%) INF, N.48 (5.7\%) TCZ, N.35 (4,2\%) ABA, N.30 (3,6\%) CTZ, N.22 (2,6\%) GOL. Median survival on treatment was 19.9 months (7.9-45.1).

Monotherapy was associated with a lower age, longer disease duration, a consistently higher Charlson Comorbidity Index (in particular hepatic or renal disease), lower GCs and NSAIDs intake. 